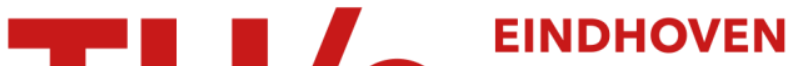 UNIVERSITY OF TECHNOLOGY
}

\section{Role of adsorbed water on charge carrier dynamics in photoexcited TiO2}

\section{Citation for published version (APA):}

Litke, A., Su, Y., Tranca, I., Weber, T., Hensen, E. J. M., \& Hofmann, J. P. (2017). Role of adsorbed water on charge carrier dynamics in photoexcited $\mathrm{TiO}_{2}$. Journal of Physical Chemistry C, 121(13), 7514-7524.

https://doi.org/10.1021/acs.jpcc.7b00472

DOI:

10.1021/acs.jpcc.7b00472

Document status and date:

Published: 06/04/2017

\section{Document Version:}

Publisher's PDF, also known as Version of Record (includes final page, issue and volume numbers)

\section{Please check the document version of this publication:}

- A submitted manuscript is the version of the article upon submission and before peer-review. There can be important differences between the submitted version and the official published version of record. People interested in the research are advised to contact the author for the final version of the publication, or visit the $\mathrm{DOI}$ to the publisher's website.

- The final author version and the galley proof are versions of the publication after peer review.

- The final published version features the final layout of the paper including the volume, issue and page numbers.

Link to publication

\section{General rights}

Copyright and moral rights for the publications made accessible in the public portal are retained by the authors and/or other copyright owners and it is a condition of accessing publications that users recognise and abide by the legal requirements associated with these rights.

- Users may download and print one copy of any publication from the public portal for the purpose of private study or research.

- You may not further distribute the material or use it for any profit-making activity or commercial gain

- You may freely distribute the URL identifying the publication in the public portal.

If the publication is distributed under the terms of Article 25fa of the Dutch Copyright Act, indicated by the "Taverne" license above, please follow below link for the End User Agreement:

www.tue.nl/taverne

Take down policy

If you believe that this document breaches copyright please contact us at:

openaccess@tue.nl

providing details and we will investigate your claim. 


\title{
Role of Adsorbed Water on Charge Carrier Dynamics in Photoexcited $\mathrm{TiO}_{2}$
}

\author{
Anton Litke, Yaqiong Su, Ionut Tranca, Thomas Weber, Emiel J. M. Hensen,*우 and Jan P. Hofmann*(0) \\ Laboratory of Inorganic Materials Chemistry, Department of Chemical Engineering and Chemistry, Eindhoven University of \\ Technology, P.O. Box 513, 5600MB Eindhoven, The Netherlands
}

\section{Supporting Information}

ABSTRACT: Overall photocatalytic water splitting is one of the most sought after processes for sustainable solar-tochemical energy conversion. The efficiency of this process strongly depends on charge carrier recombination and interaction with surface adsorbates at different time scales. Here, we investigated how hydration of $\mathrm{TiO}_{2} \mathrm{P} 25$ affects dynamics of photogenerated electrons at the millisecond to minute time scale characteristic for chemical reactions. We used rapid scan diffuse-reflectance infrared Fourier transform spectroscopy (DRIFTS). The decay of photogenerated electron absorption was substantially slower in the presence of associated water. For hydrated samples, the charge carrier recombination rates followed an Arrhenius-type behavior in

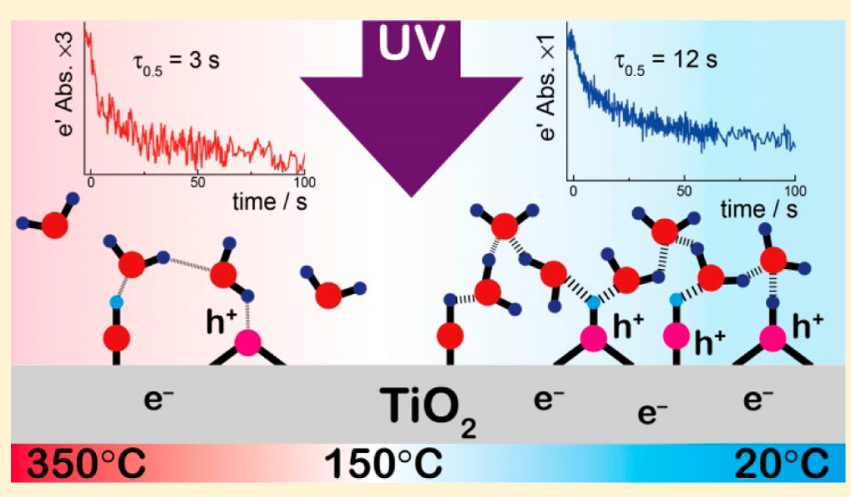
the temperature range of $273-423 \mathrm{~K}$; these became temperature-independent when the material was dehydrated at temperatures above $423 \mathrm{~K}$ or cooled below $273 \mathrm{~K}$. A DFT $+U$ analysis revealed that hydrogen bonding with adsorbed water stabilizes surfacetrapped holes at anatase $\mathrm{TiO}_{2}(101)$ facet and lowers the barriers for hole migration. Hence, hole mobility should be higher in the hydrated material than in the dehydrated system. This demonstrates that adsorbed associated water can efficiently stabilize photogenerated charge carriers in nanocrystalline $\mathrm{TiO}_{2}$ and suppress their recombination at the time scale up to minutes.

\section{INTRODUCTION}

Fossil fuels have been the primary energy source of mankind since industrialization, while in the last decades sustainable and environmentally benign alternative energy sources attract increasing attention in research. Solar light can become one of the main sources of sustainable energy in the future. However, the intermittent nature of solar energy requires scalable technologies for its harvesting and converting into storable and transportable energy carriers. In this regard, production of liquid or gaseous chemical fuels (e.g., $\mathrm{H}_{2}$, formic acid, alcohols, or light hydrocarbons) by solar-energy-driven water splitting and carbon dioxide reduction is seen as a promising option. ${ }^{1,2}$ Production of these so-called solar fuels can be facilitated by a suitable photocatalytic material that combines light harvesting and redox functions. Typical photocatalysts are inorganic semiconductors, and titanium dioxide is the most widely studied material. ${ }^{3,4}$ This wide band gap $(3.0-3.2 \mathrm{eV})$ oxide finds application in water splitting, ${ }^{4}$ dye-sensitized solar cells, ${ }^{5}$ and photocatalytic remediation of pollutants. ${ }^{6}$

The energy conversion efficiency of most semiconductorbased systems remains low (in most cases $<1 \%$ ) due to a mismatch between the lifetime of photogenerated charge carriers (femtoseconds to nanoseconds) and slow kinetics of the redox reaction (milliseconds to minutes), resulting in severe electron-hole recombination. Therefore, understanding of the semiconductor bulk and interfacial charge carrier dynamics and how they couple to surface redox processes is key to optimizing photocatalytic systems. Over the last decades, titania has become a "guinea pig" of photocatalytic research, and the mixed-phase commercial pigment Aeroxide P25 (ca. 75-80\% anatase, $25-20 \%$ rutile) is an example of an extensively studied $\mathrm{TiO}_{2}$-based material that is frequently used as benchmark photocatalyst. $^{7-13}$ The charge carrier dynamics in $\mathrm{TiO}_{2}$-based materials have been investigated by different spectroscopic techniques such as transient microwave conductivity (trMC), ${ }^{14}$ photoluminescence (PL), ${ }^{15}$ transient absorption spectroscopy (TAS), ${ }^{16}$ electronic paramagnetic resonance (EPR), ${ }^{17}$ and stimulated desorption. ${ }^{18}$ These methods provide information about charge carrier trapping and recombination (trMC, TAS, stimulated desorption) as well as the nature (EPR) and depth (PL) of the trap states.

Among them, infrared spectroscopy has proven to be a versatile tool since it can simultaneously assess light-induced changes of surface groups and adsorbates ${ }^{19-21}$ and the majority charge carriers. ${ }^{22}$ Over the last decades, steady-state and timeresolved IR spectroscopy was used to study electrons in n-type $\mathrm{TiO}_{2}{ }^{8-10,23}$ Both free conduction band and shallow trapped

Received: January 16, 2017

Revised: March 13, 2017

Published: March 13, 2017 
electrons (CBE and STE, respectively) interact with electromagnetic irradiation and give rise to specific electronic absorption in the IR region. Absorption $(A)$ due to CBE is featureless, and its intensity exponentially increases with the decrease of the probing light energy:

$$
A^{\mathrm{CBE}}(\nu)=K \nu^{-n}
$$

where $\nu$ is the frequency of the probing light in wavenumbers, $K$ is the proportionality coefficient, and $n$ is an exponent which can take values between 1.5 and 3.5 depending on the electron scattering mode. ${ }^{22}$ Contrary to CBE, STE manifest themselves by broad structured bands. Optical transitions due to STE can be described, for instance, as excitation of electrons from shallow donor states into the conduction band continuum:

$$
A^{\mathrm{STE}}(E)=K \frac{\left(E-E_{\mathrm{op}}\right)^{3 / 2}}{E\left(E-E_{\mathrm{op}}+E_{\text {thermal }}\right)^{4}}
$$

where $E$ is the energy of IR irradiation in electronvolts, $K$ is the proportionality coefficient, $E_{\mathrm{op}}$ is the energy of the IR light required to excite an electron from the shallow state into the conduction band continuum, and $E_{\text {thermal }}$ is the thermal ionization energy of the donor state. ${ }^{24,25}$

Even though charge carrier dynamics in $\mathrm{TiO}_{2}$-based materials have been extensively studied over the last decades, ${ }^{8-13,23,26,27}$ there are still some discrepancies regarding the role of surface hydroxyls and adsorbed water in trapping and recombination of photogenerated charge carriers. For instance, it has been reported that dehydroxylation of $\mathrm{TiO}_{2}$ at elevated temperatures slows down the decay of photogenerated electron absorption from minutes to hours. ${ }^{8}$ On the contrary, a recent timeresolved IR study revealed that water adsorbed on nanocrystalline anatase increases the yield of photogenerated electrons and slows down their recombination at the picosecond to nanosecond time scale due to trapping of photogenerated holes by adsorbed water. ${ }^{27,28}$ In keeping with this, Panarelli et al. showed that surface-trapped holes in $\mathrm{TiO}_{2}$ only exist in the presence of adsorbed water. ${ }^{17}$

In this work we investigated how hydration of $\mathrm{TiO}_{2} \quad \mathrm{P} 25$ affects the dynamics of photogenerated electrons at the millisecond to minute time scale in order to better understand its effect on charge carrier trapping and recombination. To this end, we used rapid scan time-resolved diffuse-reflectance infrared Fourier transform spectroscopy (DRIFTS). We found that dehydration of $\mathrm{TiO}_{2}$ at $T>423 \mathrm{~K}$ accelerates charge carrier recombination and leads to a reversible hysteresis of charge carrier dynamics. Oxidative treatment altered the hydration state of $\mathrm{TiO}_{2} \mathrm{P} 25$ and induced formation of a prominent STE signal and slowed down its decay rates. Temperature-dependent measurements revealed low activation energies of the electron absorption decay rates in hydrated samples. $\mathrm{Ab}$ initio $\mathrm{DFT}+U$ analysis of the holes trapped on anatase $\mathrm{TiO}_{2}(101)$ revealed that they are more stable and mobile on hydrated surface than in the dehydrated system. These findings demonstrate that adsorbed associated water stabilizes surface-trapped photogenerated holes in $\mathrm{TiO}_{2} \mathrm{P} 25$ and suppresses charge carrier recombination at the millisecond to minute time scale characteristic for chemical reactions.

\section{EXPERIMENTAL AND COMPUTATIONAL METHODS}

2.1. Materials and Characterization. Commercial mixedphase $\mathrm{TiO}_{2}$ (Aeroxide P25, Evonik Industries) was used in all experiments. The morphology of the material was characterized by bright field transmission electron microscopy with an FEI Technai G2 (type Sphera) electron microscope operated at 200 $\mathrm{kV}$. X-ray diffractograms were collected on a Bruker Endeavor D2 powder diffractometer equipped with a Bragg-Brentano goniometer, a $\mathrm{Cu}$ cathode, and a 1D LYNXEYE detector (nickel-filtered $\mathrm{K}_{\beta}, 1.0 \mathrm{~mm}$ primary beam slit and $3.0 \mathrm{~mm}$ beam knife height). Diffuse-reflectance UV-vis spectra were recorded with a Shimadzu UV-2401PC UV-vis spectrometer equipped with an integrating sphere accessory, using $\mathrm{BaSO}_{4}$ as reference.

2.2. FTIR Spectroscopy. A Bruker Vertex 70v FTIR spectrometer equipped with a Praying Mantis diffusereflectance accessory (Harrick Scientific) and a liquid-nitrogen cooled MCT detector was used for the diffuse-reflectance infrared Fourier transform spectroscopy (DRIFTS) measurements. The IR measurements and sample treatment were carried out in an in situ DRIFTS low-temperature reaction chamber (Harrick Scientific) equipped with two $\mathrm{KBr}$ and one fused-silica windows for IR signal collection and sample irradiation, respectively. The cell was connected to a homebuilt gas delivery system. During all experiments, the temperature of the cell exterior was maintained at $293 \mathrm{~K}$ by cooling water. The sample compartment of the spectrometer was purged with dry nitrogen during all experiments. The spectra were recorded at $4 \mathrm{~cm}^{-1}$ resolution in the spectral range of $3950-600 \mathrm{~cm}^{-1}$. Steady-state spectra reported in this work are averages of 100 scans. A low-pass IR filter (cutoff frequency $3950 \mathrm{~cm}^{-1}$ ) was placed in front of the detector compartment to block stray light and reflected laser irradiation. $\mathrm{KBr}$ (SigmaAldrich, IR grade) was used as reference for the survey DRIFT spectra. Typically, the spectrum of the sample in the dark was used as the reference for difference spectra and in time-resolved measurements.

Time-resolved DRIFT measurements were conducted in rapid scan mode. The following settings were used: $4 \mathrm{~cm}^{-1}$ spectral resolution, $40 \mathrm{kHz}$ scanner velocity, acquisition of single-sided interferograms at forward and backward mirror movement with automatic splitting of the interferograms by Bruker OPUS 7.5 software. With these settings, a single scan took ca. $125 \mathrm{~ms}$ and the delay between consecutive scans was ca. $40 \mathrm{~ms}$. Temporal profiles of the IR signal at particular wavenumbers were extracted by Bruker OPUS 7.5 from the $3 \mathrm{D}$ data blocks consisting of transient spectra stacked against the delay time. Resulting temporal profiles were processed in Origin 9.0. In case the signal-to-noise ratio was poor, results of several independent measurements were averaged during data processing. $\mathrm{O}_{2} \quad(\geq 99.95 \%), \mathrm{H}_{2} \quad(\geq 99.999 \%)$, and $\mathrm{Ar}$ $(\geq 99.999 \%)$ gases were supplied by Linde and passed through moisture and/or oxygen filters (Agilent Technologies). The $325 \mathrm{~nm}$ emission line of a continuous-wave $\mathrm{He}-\mathrm{Cd}$ laser (Kimmon Koha) was used to irradiate samples. The light intensity at the fused-silica window was ca. $10 \mathrm{~mW} / \mathrm{cm}^{2}$ in all experiments. Exposure of the sample (60 s for time-resolved measurements) was controlled by a software script and an optical shutter (Thorlabs). The spectrometer was used as the master in all experiments. More details on data conversion and processing can be found in the Supporting Information (cf. also Figure S1).

2.3. Sample Treatment. Titania samples were pretreated in five different ways. Untreated $\mathrm{TiO}_{2}$ (sample i) was prepared by keeping as-delivered $\mathrm{TiO}_{2} \mathrm{P} 25$ in the spectroscopic cell under dynamic vacuum $\left(p<10^{-3}\right.$ mbar) for $4-5 \mathrm{~h}$ at $293 \mathrm{~K}$ prior to the experiments. Room-temperature dehydrated $\mathrm{TiO}_{2}$ (sample ii) was prepared by keeping as-delivered $\mathrm{TiO}_{2}$ P25 at 
$293 \mathrm{~K}$ under dynamic vacuum for $36 \mathrm{~h}$. Dehydrated titania (sample iii) was prepared by heating $\mathrm{TiO}_{2}$ to $623 \mathrm{~K}$ for $1-2 \mathrm{~h}$ under dynamic vacuum followed by cooling to room temperature under static vacuum. Rehydrated sample (sample iv) was prepared with the same procedure as sample iii but the sample was kept for $16 \mathrm{~h}$ in 300 mbar dry Ar after cooling down to 293 $\mathrm{K}$. Residual water in the $\operatorname{Ar}$ stream $(<0.1 \mathrm{ppm})$ and water desorbed from the cell interior rehydrated the sample during this hold time. The oxidized sample (sample v) was prepared by heating titania to $523 \mathrm{~K}$ under dynamic vacuum, followed by irradiation with a $325 \mathrm{~nm}$ laser $\left(10 \mathrm{~mW} / \mathrm{cm}^{2}\right)$ under static vacuum for $1 \mathrm{~h}$. Subsequently, the reaction chamber was filled with 50 mbar $\mathrm{O}_{2}$ and the sample was irradiated with the UV light again until a stable spectrum was obtained. After this, the reaction chamber was evacuated, refilled with $50 \mathrm{mbar} \mathrm{O}_{2}$, cooled to room temperature, and then the sample was exposed to UV light for $30 \mathrm{~min}$ in the presence of oxygen. The resulting material (sample v) was stored in $300 \mathrm{mbar}_{2}$ overnight in dark prior to further spectroscopic experiments. The color of $\mathrm{TiO}_{2}$ samples did not turn blue or gray upon prolonged evacuation and/or heating, which indicated that no substantial reduction of the studied materials took place under the chosen experimental conditions.

2.4. Computational Analysis. All calculations were performed using the Vienna $a b$ initio simulation package (VASP). ${ }^{29}$ The ion-electron interactions were represented by the projector-augmented wave (PAW) method ${ }^{30}$ and the electron exchange-correlation by the generalized gradient approximation (GGA) with the Perdew-Burke-Ernzerhof (PBE) exchange-correlation functional. ${ }^{31}$ We carried out spinpolarized calculations. The Kohn-Sham valence states were expanded in a plane-wave basis set with a cutoff energy of 400 $\mathrm{eV}$. We have used the DFT $+U$ approach, in which $U$ is a Hubbard-like term describing the on-site Coulombic interactions. ${ }^{32}$ This approach improves the description of localized states in titania, where standard LDA and GGA functionals fail. The values of $U(\mathrm{Ti})=4.2 \mathrm{eV}$ and $U(\mathrm{O})=5.25 \mathrm{eV}$ were applied to the $\mathrm{Ti} 3 \mathrm{~d}$ and $\mathrm{O} 2 \mathrm{p}$ states, which have been used previously to successfully localize the electrons and holes in n- and p-type defect states in titania, in agreement with experimental EPR data. $^{33}$

Our calculated GGA + U lattice parameters for anatase titania were $a=3.907 \AA$ and $c=9.724 \AA .{ }^{34}$ The anatase $\mathrm{TiO}_{2}(101)$ surface - the most abundant and most stable facet exposed in $\mathrm{TiO}_{2} \mathrm{P} 25$ - was modeled by a periodic slab using a $3 \times 3$ supercell consisting of seven layers of in total $63 \mathrm{TiO}_{2}$ units. The vacuum gap was set to $15 \AA$. The bottom three layers were frozen to their bulk position, and the four top $\mathrm{Ti}-\mathrm{O}-\mathrm{Ti}$ layers were allowed to relax. Twelve water molecules were adsorbed on anatase $\mathrm{TiO}_{2}(101)$ surface to simulate the hydrated interface (Figure S2, Supporting Information). Due to the large cell size, $k$-point sampling was restricted to the $\Gamma$ point. The climbing image nudged-elastic band (CI-NEB) algorithm $^{35,36}$ was used to identify the transition states for the trapped hole migration on the anatase $\mathrm{TiO}_{2}(101)$ surface.

\section{RESULTS AND DISCUSSION}

3.1. Dynamics of Photogenerated Electrons in Untreated $\mathrm{TiO}_{2}$ P25. The dark survey spectrum of untreated P25 $\mathrm{TiO}_{2}$ (sample i) is shown in Figure 1. The most prominent bands at ca. $3400 \mathrm{~cm}^{-1}$ (broad) and $1622 \mathrm{~cm}^{-1}$ correspond to the stretching and bending vibrations of adsorbed associated water, respectively (cf. Table 1 for IR spectral assign-

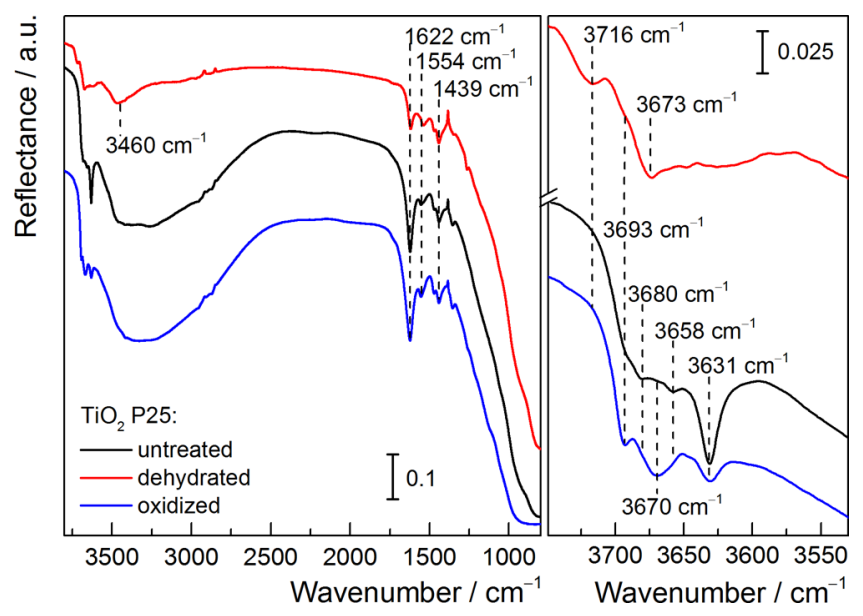

Figure 1. Left: room-temperature dark DRIFT spectra of $\mathrm{TiO}_{2} \mathrm{P} 25$ in static vacuum: untreated sample i (black), dehydrated sample iii (red), oxidized sample v (blue). Right: zoomed in $\mathrm{O}-\mathrm{H}$ stretching region. Note: the spectra are vertically offset for convenience.

ments). ${ }^{37-39}$ The presence of hydroxyls on the anatase and rutile phases was evident from the bands at 3716, 3693, 3680, 3658 , and $3631 \mathrm{~cm}^{-1}$. The bands in the $2980-2840 \mathrm{~cm}^{-1}$ region indicate the presence of hydrocarbon moieties, while those at 1554 and $1439 \mathrm{~cm}^{-1}$ can be attributed to oxygenates and/or carbonates. These organic compounds resulted from adsorption of ambient contaminants on as-delivered $\mathrm{TiO}_{2}$ P25. ${ }^{40,41}$

When the untreated sample $\mathrm{i}$ was exposed to $325 \mathrm{~nm}$ irradiation, a broad featureless absorption band developed in the $2900-1000 \mathrm{~cm}^{-1}$ region while the IR bands of adsorbed water and surface hydroxyls decreased in intensity (Figure 2). These spectral changes reversed in the dark. Intensity of the featureless absorption band increased toward lower wavenumbers and could be reliably fit with function 1 characteristic for CBE. The best fit was achieved with $n=1.6 \pm 0.1$ in good agreement with previous reports. ${ }^{8-12,23}$ This band was hardly affected by addition of $\mathrm{Ar}$, while molecular oxygen substantially quenched its intensity (Figure S3, Supporting Information), which further confirms its assignment to photogenerated electron.

Similar to previous reports, ${ }^{8-12}$ the decay rates of the photogenerated electron absorption band were wavenumberindependent in the $2900-1000 \mathrm{~cm}^{-1}$ range. Therefore, we monitored its transient behavior at $1205 \mathrm{~cm}^{-1}$, where no molecular bands were present (Figure 3, black curve). The electron absorption decay in the dark showed a complex behavior. Within the first minute the signal intensity decreased to ca. $30 \%$ of its initial value and then decayed to zero at much slower rates. A reliable fit of the initial part of the kinetic curve was achieved with either a second-order decay or a sum of two exponents. Both models gave similar $R^{2}$ values and half-life times of the signal decay: $(11.8 \pm 0.3) \mathrm{s}$ (Table 2$)$. The slow signal decay from ca. 1 min onward followed first-order kinetics with a half-life time of $2 \mathrm{~min}$. No reliable fit of the kinetic curves in the broad time range $(\geq 5 \mathrm{~min})$ could be achieved when only a second-order or a two-exponential model was used, but rather a sum of first- and second-order decays or a three-exponential model was needed.

Such a complex decay of the photogenerated electron absorption may stem from different phenomena. First, if the observed signal originates from well-defined single species (i.e., 
Table 1. Characteristic IR Bands and Their Assignment

\begin{tabular}{|c|c|c|c|}
\hline this work $\left(\mathrm{cm}^{-1}\right)$ & band assignment & literature values $\left(\mathrm{cm}^{-1}\right)$ & refs \\
\hline 3734 & terminal $\mathrm{O}-\mathrm{H}$, anatase & 3734 & 42,43 \\
\hline $3715-3720$ & terminal $\mathrm{O}-\mathrm{H}$, anatase & 3715 & $38,42,44$ \\
\hline $3690-3695$ & dissociatively adsorbed water on rutile and anatase $\mathrm{TiO}_{2}$ & $3693-3695$ & 45,46 \\
\hline $3683-3680$ & surface $\mathrm{O}-\mathrm{H}$, rutile & $3680-3685$ & 38,44 \\
\hline 3673 & terminal or bridged $\mathrm{O}-\mathrm{H}$, anatase & 3675 & 38,43 \\
\hline 3658 & hydrogen-bonded or isolated surface $\mathrm{O}-\mathrm{H}$, rutile & 3655 & 44,47 \\
\hline 3631 & dissociatively adsorbed water on nanocrystalline anatase & 3630 & $42,48,49$ \\
\hline 3618 & surface $\mathrm{O}-\mathrm{H}$, rutile & 3615,3610 & 37,47 \\
\hline 3460 & antisymmetric stretching of water in multimeric species & 3455 & 50 \\
\hline 3400 (broad) & hydrogen-bonded adsorbed water & 3400 & 37,51 \\
\hline $2980-2840$ & $-\mathrm{CH}_{3},-\mathrm{CH}_{2}-$ stretching & $2985-2840$ & 40 \\
\hline 2349 & gaseous $\mathrm{CO}_{2}$ & 2349 & 40 \\
\hline $1640-1620$ & water bending & $1630-1605$ & 38,39 \\
\hline 1554 & carboxylate antisymmetric stretching & $1610-1550$ & 40,41 \\
\hline 1439 & carboxylate symmetric stretching, $-\mathrm{CH}_{2}-$ scissoring & $1420-1300$ and $1480-1440$ & 38,41 \\
\hline
\end{tabular}

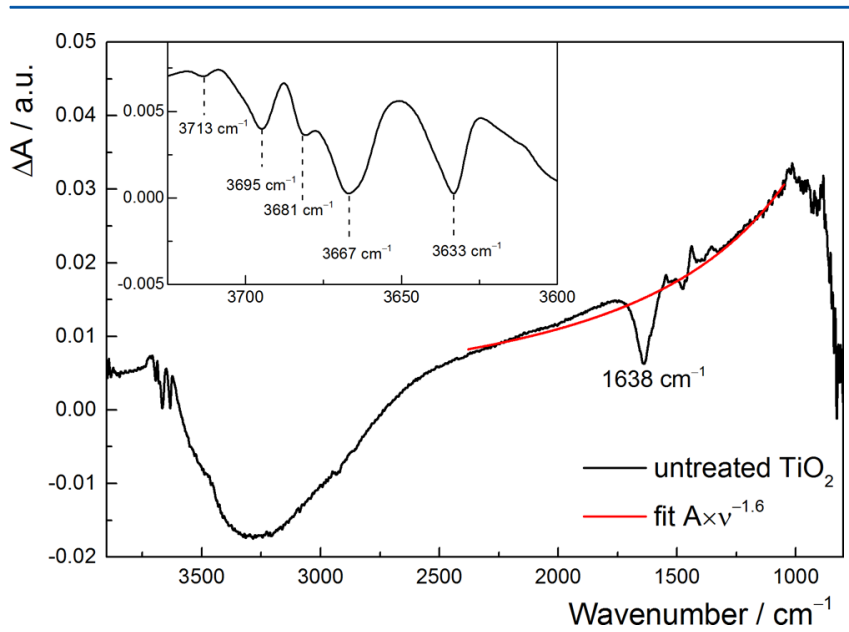

Figure 2. Room-temperature DRIFT difference spectrum of untreated $\mathrm{TiO}_{2}$ P25 (sample i) in a static vacuum under $325 \mathrm{~nm}$ irradiation (black curve) and the exponential fit of the experimental data (red curve). Inset: zoomed in $\mathrm{O}-\mathrm{H}$ stretching region.

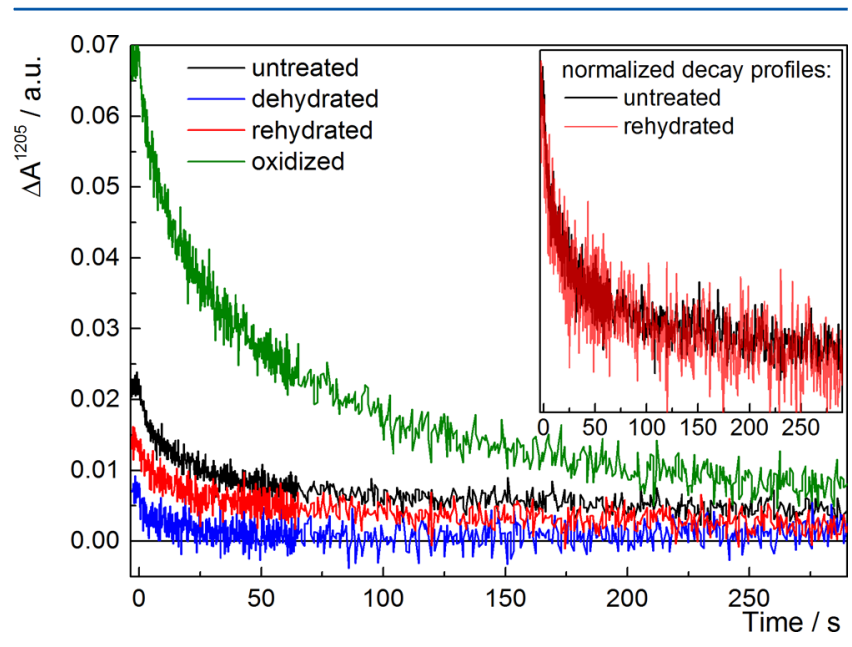

Figure 3. Decay profiles of the photogenerated electron absorption at $1205 \mathrm{~cm}^{-1}$. $\mathrm{TiO}_{2}$ P25 samples subjected to different treatments: black, untreated sample i; red, sample iii dehydrated at $623 \mathrm{~K}$; blue, rehydrated sample iv; green, oxidized sample v. Inset: normalized decay curves of untreated and rehydrated samples. Temporal profiles were recorded after $60 \mathrm{~s}$ of exposure to $325 \mathrm{~nm}$ irradiation at $293 \mathrm{~K}$ under static vacuum.
Table 2. Half-Life Time of the Second-Order Signal Decay at $1205 \mathrm{~cm}^{-1}$ (293 K, Vacuum)

\begin{tabular}{clll} 
sample $\mathrm{TiO}_{2}$ & \multicolumn{1}{c}{ treatment $^{a}$} & \multicolumn{1}{c}{$\tau_{1} / \mathrm{s}$} & \multicolumn{1}{c}{$\tau_{2} / \mathrm{min}$} \\
$\mathrm{i}$ & untreated & $11.8 \pm 0.3$ & $1.8 \pm 0.5$ \\
ii & room-temperature dehydrated & $4.0 \pm 0.2$ & N.A. \\
iii & dehydrated at $623 \mathrm{~K}$ & $2.9 \pm 0.5$ & N.A. \\
iv & rehydrated & $13.2 \pm 0.8$ & $2.0 \pm 0.6$ \\
v & oxidized & $61.5 \pm 2.0$ & $3.6 \pm 0.5$
\end{tabular}

${ }^{a}$ For details on sample treatment see the Experimental and Computational Methods section. ${ }^{b}$ N.A.: not available.

$\mathrm{CBE}$ ), then faster and slower decay components can correspond to at least two different charge carrier recombination channels. For instance, a faster second-order decay can correspond to bimolecular recombination of trapped electrons and holes, while a slower first-order component may be due to defect-assisted recombination. ${ }^{8}$ Second, both CBE and STE may contribute to the broad absorption band formed in the low-wavenumber region under UV irradiation (Figure 2). ${ }^{25}$ In this case, faster and slower decay components may arise from the recombination of photogenerated holes with CBE and STE, respectively. Finally, a combination of both situations cannot be excluded which severely complicates the development of a reliable analytical model. In this study we opted for the sum of first- and second-order decays to fit the data over a broad time range, while the second-order decay kinetics was used to fit fast initial decay of the signal (for more details on the fitting procedure see Supporting Information).

3.2. Faster Charge Carrier Recombination in Dehydrated $\mathrm{TiO}_{2} \mathbf{P} 25$. Szczepankiewicz et al. have previously reported that dehydroxylation of $\mathrm{TiO}_{2}$ P25 slows down the decay of photogenerated electrons from minutes to hours. ${ }^{8}$ On the other hand, a recent study of photogenerated electron dynamics at the picosecond to nanosecond time scale shows that adsorbed water suppresses charge carrier recombination in anatase $\mathrm{TiO}_{2}{ }^{27,28}$ In order to evaluate whether adsorbed water has a positive or an adverse effect on the charge carrier recombination at the millisecond to minute time scale, we studied photogenerated electron absorption dynamics in the material which was dehydrated under dynamic vacuum $(p<$ $10^{-3}$ mbar) at $623 \mathrm{~K}$ (sample iii). The room-temperature dark DRIFT spectrum of this sample is shown in Figure 1 (red curve). As expected, for this sample the intensities of adsorbed 
water and surface hydroxyls bands were substantially lower than for untreated $\mathrm{TiO}_{2}$. The $\mathrm{O}-\mathrm{H}$ stretching region of sample iii contained two well-resolved bands at 3716 and $3673 \mathrm{~cm}^{-1}$, while the bands at 3680,3658 , and $3631 \mathrm{~cm}^{-1}$ were almost absent (Figure 1, red curve). The bending vibration band of adsorbed water at $1620 \mathrm{~cm}^{-1}$, which was absent in the spectrum recorded at $623 \mathrm{~K}$ (Figure S4, Supporting Information), reappeared upon cooling, but with lower intensity than before the treatment. The broad band of hydrogen-bonded hydroxyls and associated water $\left(3400 \mathrm{~cm}^{-1}\right)$ was diminished to a weaker well-resolved feature at $3460 \mathrm{~cm}^{-1}$. This band can be assigned to the asymmetric stretching mode of water molecules present in the form of small clusters (Table 1). ${ }^{50}$

The difference spectrum formed in sample iii under $325 \mathrm{~nm}$ irradiation is shown in Figure 4, black curve. UV excitation

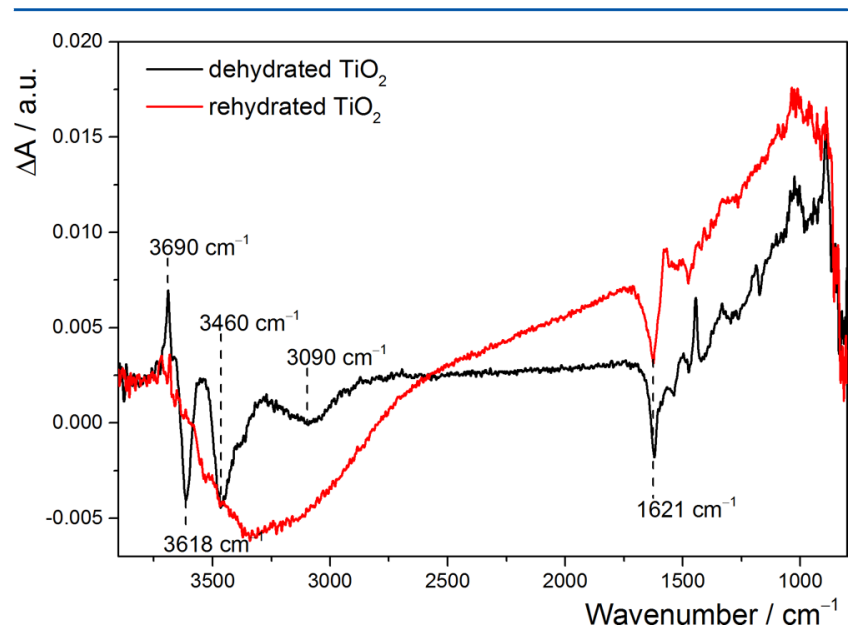

Figure 4. Difference room-temperature DRIFT spectra of dehydrated sample iii (black) and rehydrated sample iv (red) $\mathrm{TiO}_{2} \mathrm{P} 25$ in static vacuum under $325 \mathrm{~nm}$ irradiation.

decreased intensities of the bands at 3618, 3460, 3090, and $1621 \mathrm{~cm}^{-1}$, while a well-resolved band at $3690 \mathrm{~cm}^{-1}$ and a broad feature in the $1600-900 \mathrm{~cm}^{-1}$ region emerged. The band at $3618 \mathrm{~cm}^{-1}$ was due to surface hydroxyls of rutile $\mathrm{TiO}_{2}$, while the 3460 and $1621 \mathrm{~cm}^{-1}$ bands corresponded to stretching and bending vibrations of adsorbed water, respectively. The band at $3690 \mathrm{~cm}^{-1}$ can be ascribed to water dissociatively adsorbed on anatase and/or rutile $\mathrm{TiO}_{2}$ (Table 1). ${ }^{45,46}$ The broad absorption feature formed in the region below $1600 \mathrm{~cm}^{-1}$ could be fit with function 1 , and its intensity was quenched in the presence of $\mathrm{O}_{2}$, confirming its $\mathrm{CBE}$ origin. Compared with sample i (Figure 2), this band had lower intensity, its onset shifted toward lower wavenumbers, and it decayed at substantially faster rates. The half-life decay time decreased from $(11.8 \pm 0.3)$ s to $(2.9 \pm 0.5)$ s upon $\mathrm{TiO}_{2}$ dehydration (Table 2). Moreover, in the dehydrated sample CBE absorption decayed to zero after already $30 \mathrm{~s}$ in the dark without a prominent slow component (Figure 3). Contrary to the work of Szczepankiewicz et al., ${ }^{8}$ our results demonstrate the adverse effect of dehydration on the charge carrier lifetime in $\mathrm{TiO}_{2} \mathrm{P} 25$.

When sample iii was left in the in situ DRIFTS lowtemperature reaction chamber in $300 \mathrm{mbar}$ Ar for $16 \mathrm{~h}$, it was partially rehydrated by residual water in $\operatorname{Ar}(<0.1 \mathrm{ppm})$ and water desorbed from the internal cell walls (sample iv). This was evident by the bands at $3675,3655,3630$, and $3400 \mathrm{~cm}^{-1}$ which reappeared in the IR spectrum but with lower intensities than before (Figure S5, Supporting Information). Both the difference spectrum produced in sample iv by $325 \mathrm{~nm}$ irradiation (Figure 4, red curve) and the decay rates of the photogenerated electron absorption (Figure 3, inset) were similar to those of the untreated material (Figure 2), except for the intensities of these spectral features. This suggests that the amount of water adsorbed on titania strongly affects the apparent electron absorption intensity (i.e., the number of photogenerated charge carriers) but not the room-temperature charge carrier dynamics. The reversible effect of dehydration and slower charge carrier recombination rates found for the hydrated samples (Table 2) demonstrate that adsorbed water substantially slows down electron-hole recombination in $\mathrm{TiO}_{2}$ at the millisecond to minute time scale.

3.3. Influence of Adventitious Organic Adsorbates on Charge Carrier Dynamics. The above-discussed experimental results show that dehydration of $\mathrm{TiO}_{2}$ adversely affects both the intensity of photogenerated electron absorption and its lifetime. On the other hand, adventitious organic adsorbates can influence photogenerated charge carrier dynamics as well. ${ }^{8,9,52,53}$ The untreated $\mathrm{TiO}_{2}$ P25 exhibited vibrational bands at 2980-2840, 1554, and $1439 \mathrm{~cm}^{-1}$ (Figure 1) due to hydrocarbons, organic oxygenates, and/or carbonates (Table 1 ). In order to remove these adventitious adsorbates we oxidized the material at $523 \mathrm{~K}$ in $100 \mathrm{mbar}_{2}$. When the sample was heated in the dark, the intensities of the bands at 2980-2840 $\mathrm{cm}^{-1}$ decreased, a new band emerged at 2349 $\mathrm{cm}^{-1}$, and the bands at 1554 and $1439 \mathrm{~cm}^{-1}$ became stronger. These spectral changes evidenced oxidation of adsorbates containing hydrocarbon moieties to gas-phase $\mathrm{CO}_{2}$ and carboxylates (Table 1). After about $1 \mathrm{~h}$, the intensities of these changes became stable and were not affected by the addition of oxygen or increase of the treatment time. The remaining hydrocarbons and formed carboxylates were further oxidized to $\mathrm{CO}_{2}$ when the material was irradiated with $325 \mathrm{~nm}$ light at $523 \mathrm{~K}$ in $100 \mathrm{mbar}_{2}$. When the resulting sample was cooled to room temperature either under static vacuum or in dry $\mathrm{Ar}$, its behavior under UV irradiation did not differ from that of the non-oxidized dehydrated material. This suggests that adventitious organic adsorbates had no significant effect on photogenerated electron dynamics at the millisecond to minute time scale.

3.4. Influence of Oxidative Post-Treatment on $\mathrm{TiO}_{2}$ Hydration and Photogenerated Electron Absorption. Unlike adventitious organic adsorbates, changes of $\mathrm{TiO}_{2}$ hydration had a very prominent effect on the photogenerated electron absorption intensity, spectral appearance, and decay rates. When the oxidized sample was cooled to room temperature in $50 \mathrm{mbar}_{2}$ instead of $\mathrm{Ar}$ or vacuum (see previous section), exposed to $325 \mathrm{~nm}$ irradiation for $30 \mathrm{~min}$, and stored overnight under the same $\mathrm{O}_{2}$ atmosphere (sample $\mathrm{v})$, the survey DRIFT spectrum exhibited stronger bands of surface hydroxyls and adsorbed water compared with untreated titania (Figure 1, blue curve). The $\mathrm{O}-\mathrm{H}$ stretching region of sample $\mathrm{v}$ showed a prominent band at $3693 \mathrm{~cm}^{-1}$ of water dissociatively adsorbed on $\mathrm{TiO}_{2}{ }^{45,46}$ This band was also present in untreated titania but only as a shoulder (Figure 1). Other differences between samples $\mathrm{i}$ and $\mathrm{v}$ included a decreased intensity of the $3631 \mathrm{~cm}^{-1}$ band and appearance of the band at $3670 \mathrm{~cm}^{-1}$. The latter band was rather broad and could include superimposed 3680 and $3658 \mathrm{~cm}^{-1}$ bands. These changes agreed well with the notion that water adsorbs more easily on 
anatase $\mathrm{TiO}_{2}$ under UV irradiation in the presence of $\mathrm{O}_{2}$ than in an inert atmosphere. ${ }^{54}$

When sample $\mathrm{v}$ was exposed to $325 \mathrm{~nm}$ irradiation the bands of adsorbed water $\left(3400,1631 \mathrm{~cm}^{-1}\right)$ and surface hydroxyls (3693, 3681, 3670, and $3634 \mathrm{~cm}^{-1}$ ) decreased in intensity (Figure 5). This was accompanied by the appearance of the

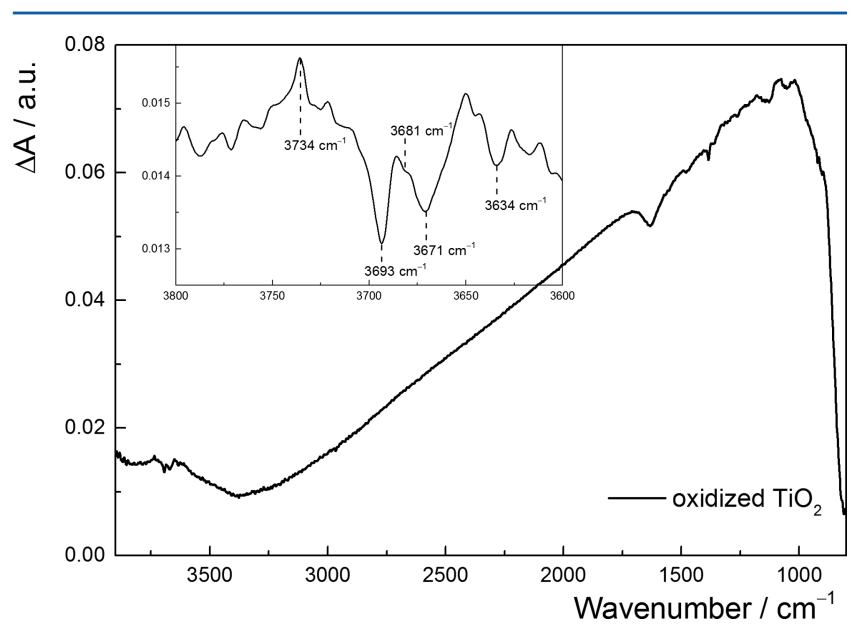

Figure 5. Difference room-temperature DRIFT spectrum of oxidized $\mathrm{P} 25 \mathrm{TiO}_{2}$ (sample v) in static vacuum under $325 \mathrm{~nm}$ irradiation. Inset: zoomed in $\mathrm{O}-\mathrm{H}$ stretching region.

band at $3734 \mathrm{~cm}^{-1}$ which was attributed to terminal hydroxyls of the anatase $\mathrm{TiO}_{2}{ }^{42,43}$ and was not observed in the untreated sample (Figure 2). Another difference between samples $\mathrm{i}$ and $\mathrm{v}$ was the rearrangement of the $\mathrm{O}-\mathrm{H}$ bands under $325 \mathrm{~nm}$ irradiation. In sample $i$ the bands at 3633 and $3667 \mathrm{~cm}^{-1}$ were affected the most, while in sample $\mathrm{v}$ the most prominent intensity change was observed for the 3671 and $3693 \mathrm{~cm}^{-1}$ bands (insets in Figures 2 and 5, respectively). Yet the most striking difference between these two samples was the intensity and the structure of photogenerated electron absorption bands. Compared with the untreated material, the band formed in sample $\mathrm{v}$ had higher intensity and did not follow exponential function 1 but almost linearly increased toward lower wavenumbers evidencing formation of species other than CBE.

3.5. Shallow Trapped Electrons (STE) in Oxidized $\mathrm{TiO}_{2}$ P25. The electron absorption formed in oxidized sample $\mathrm{v}$ under UV irradiation (Figure 5) was similar to the bands previously observed by Panayotov et al. ${ }^{25}$ The authors ascribed such bands to the overlapping absorption of the CBE and STE components. Here, we adopted the model developed by Panayotov et al. $^{25}$ to fit our experimental spectra (Figure S5, Supporting Information). From this fitting, one can see that a substantial part of the signal corresponds to STE. This accounted for the stronger photogenerated electron absorption signal observed in sample $\mathrm{v}$ and may explain its slower decay rates in comparison with untreated titania (Table 2). Despite the substantially different decay rates, the absorption signal decay profiles of sample $\mathrm{v}$ exhibited a complex behavior similar to that of the untreated and rehydrated samples (Figure 3). First, the signal decayed to ca. $25 \%$ of its initial value following the apparent second-order decay kinetics with $\tau_{0.5}=(62 \pm 2) \mathrm{s}$. Then, the remaining absorption relaxed to zero in an apparent first-order process with $\tau_{0.5}=(3.6 \pm 0.5) \mathrm{min}$ (Table 2).
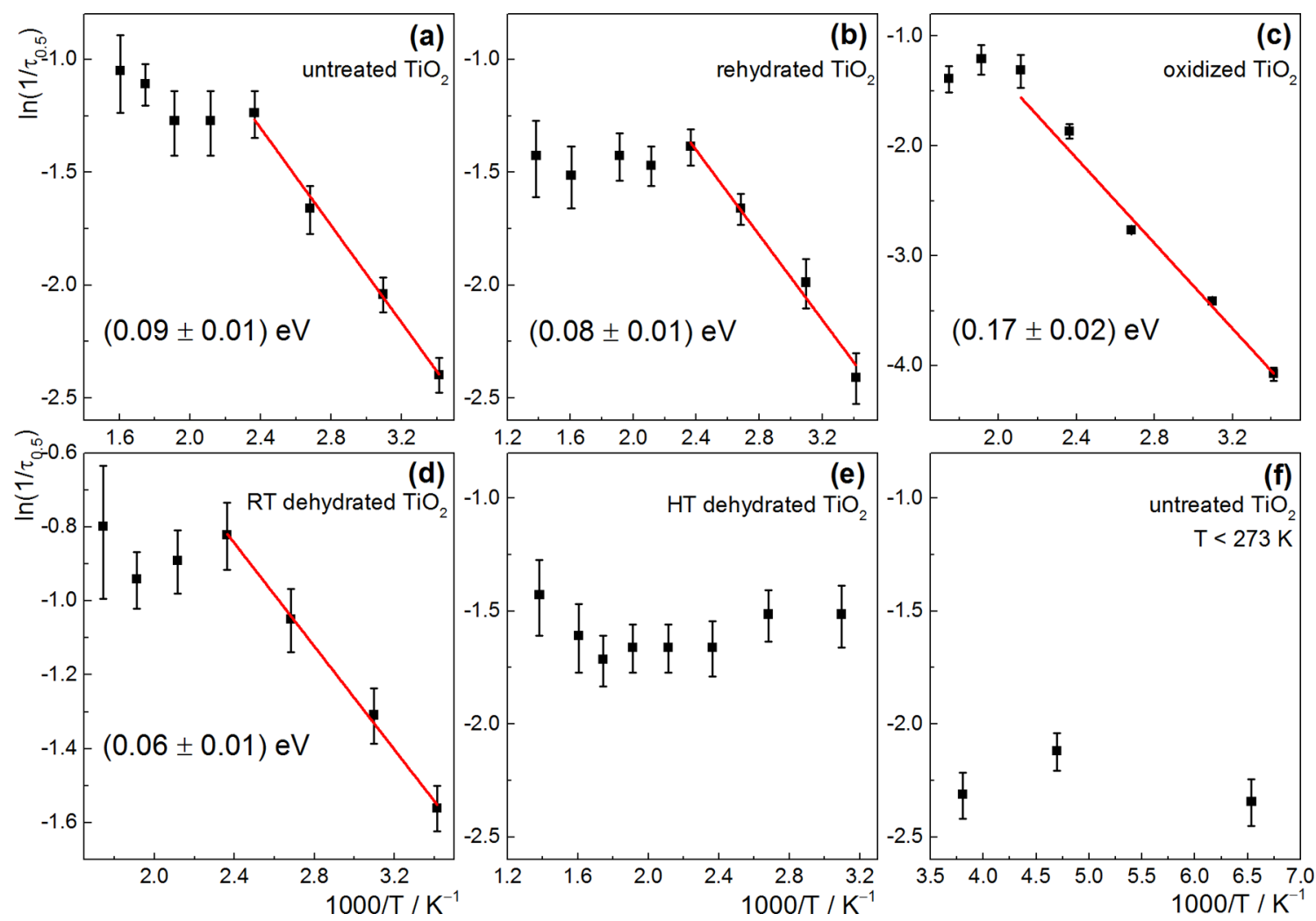

Figure 6. Temperature dependence of the characteristic electron absorption decay times found for the $\mathrm{TiO}_{2} \mathrm{P}_{2} 5$ samples subjected to different treatments: (a) untreated sample i; (b) rehydrated sample iv; (c) oxidized sample v; (d) sample ii dehydrated at room temperature for 36 h; (e) sample iii dehydrated at $623 \mathrm{~K}$; (f) untreated sample i at $T<273 \mathrm{~K}$. Values in electronvolts represent apparent activation energies derived from the linear regions of the plots (red lines). 
3.6. Influence of Hydration on Charge Carrier Recombination. Previous sections show that both the intensity of photogenerated electron absorption and its decay rates depend on $\mathrm{TiO}_{2}$ hydration. However, room-temperature measurements alone are insufficient to derive a reliable conclusion about the role of adsorbed water in the photogenerated charge carrier dynamics. This is because both CBE and STE can contribute to the apparent electron absorption (Figure S5, Supporting Information). Moreover, the studied samples exhibited a number of stretching $\mathrm{O}-\mathrm{H}$ bands whose positions and intensities were obscured by hydrogen bonding (Table 1). In order to understand how adsorbed water affects photogenerated charge carrier dynamics we studied the electron absorption decay rates as a function of temperature and pretreatment (Figure 6).

Independent from the treatment, all hydrated samples showed two distinct regimes of the electron absorption decay. In the 293-423 $\mathrm{K}$ temperature range, the apparent decay rates exhibited Arrhenius-type behavior, while they did not vary with temperature above $423 \mathrm{~K}$ (Figure $6 \mathrm{a}-\mathrm{d}$ ). It is worthwhile to mention that, above $423 \mathrm{~K}$, the bands of associated water at 3400 and $1622 \mathrm{~cm}^{-1}$, as well as the $\mathrm{O}-\mathrm{H}$ bands at 3632 and $3683 \mathrm{~cm}^{-1}$, substantially decreased in intensity in comparison with lower temperatures (Figure S4, Supporting Information). The dehydrated sample iii showed no apparent temperature dependence of the charge carrier recombination rates in the temperature range of 323-723 $\mathrm{K}$ (Figure 6e). Above $523 \mathrm{~K}$ the DRIFT spectra of sample iii exhibited mainly the bands of terminal hydroxyls at 3720 and $3670 \mathrm{~cm}^{-1}$. Below this temperature the $3460 \mathrm{~cm}^{-1}$ band emerged in the survey DRIFT spectra. This band was attributed to stretching vibrations of water adsorbed in the form of small clusters, ${ }^{50}$ and it was stable for at least 3-4 h after cooling to $293 \mathrm{~K}$ (Figure S6, Supporting Information). Eventually, the broad absorption feature of associated water with the maximum at $3400 \mathrm{~cm}^{-1}$ and the bands at 3693, 3670, and $3630 \mathrm{~cm}^{-1}$ reappeared in the survey DRIFT spectra evidencing rehydration of titania. Rehydration restored properties of the material under $325 \mathrm{~nm}$ irradiation both at $293 \mathrm{~K}$ (see section 3.2) and elevated temperatures (Figure 6b). Hence, we surmise that the hysteresis of the photogenerated charge carrier dynamics observed in $\mathrm{TiO}_{2}$ upon its heating above $423 \mathrm{~K}$ related to the association of adsorbed water. This is because sample iii exhibited fast temperature-independent charge carrier recombination (Figure 6e) while its survey DRIFT spectra evidenced the presence of terminal hydroxyls and small clusters of adsorbed water (Figure S6, Supporting Information) but not the associated water band. The latter indicates that neither terminal hydroxyls nor small water clusters can efficiently suppress electron-hole recombination in $\mathrm{TiO}_{2} \mathrm{P} 25$ at the millisecond to minute time scale. These findings agree with a recent EPR study showing that surface trapping of photogenerated holes is inefficient in anatase $\mathrm{TiO}_{2}$ dehydrated at 423 $\mathrm{K}^{17}$

From Figure 6, one can see that the apparent activation energies of the photogenerated electron absorption decay were almost identical for the untreated and rehydrated samples $(0.08-0.09 \mathrm{eV})$ and slightly lower for the sample dehydrated at room temperature $(0.06 \mathrm{eV})$. Although oxidized titania exhibited the slowest electron absorption decay rates and the highest apparent activation energy of $0.17 \mathrm{eV}$ in the $293-423 \mathrm{~K}$ temperature range, charge carrier recombination was temperature-independent above $423 \mathrm{~K}$ (Figure 6c) similar to other hydrated samples. Consequently, differences in apparent activation energies and the electron absorption decay rates can be attributed to different hydration of the materials rather than their intrinsic properties.

3.6.1. Temperature-Independent Charge Carrier Recombination at 153-263 K. From the temperature-dependent plots (Figure $6 \mathrm{a}-\mathrm{d}$ ) one can expect that cooling of the hydrated samples below $293 \mathrm{~K}$ can further slow charge carrier recombination. Contrary to this, we found that the photogenerated electron absorption decay rates were temperatureindependent between 263 and $153 \mathrm{~K}$, yet slightly faster than at $293 \mathrm{~K}$ (Figure 6f). The intensity of electron absorption at these temperatures was substantially lower than at $293 \mathrm{~K}$. Besides this, steady-state spectra of untreated $\mathrm{TiO}_{2}$ changed when it was cooled below $273 \mathrm{~K}$. The absorption bands at 3400 and $1620 \mathrm{~cm}^{-1}$ became weaker, the shoulder at $3695 \mathrm{~cm}^{-1}$ disappeared, and the $3720 \mathrm{~cm}^{-1}$ band grew in intensity compared with the sample at $293 \mathrm{~K}$ (Figure S8, Supporting Information). As water could not desorb from titania under these conditions, the aforementioned spectral changes can be explained by perturbed interaction between the oxide surface and adsorbed water. For instance, the increase of the terminal hydroxyls band intensity at $3720 \mathrm{~cm}^{-1}$ can be interpreted as weakened hydrogen bonding between adsorbed water and surface hydroxyls. $^{39}$

3.6.2. Origin of the Apparent Activation Energy. Even though the apparent activation energies obtained in this work are difficult to assign to a specific process, these values, when combined with the effect of dehydration and low temperature, provide valuable phenomenological insights about the interplay of surface hydration and charge carrier dynamics in $\mathrm{TiO}_{2} \mathrm{P} 25$ at the millisecond to minute time scale. First of all, these apparent activation energies are unlikely to directly correspond to water desorption. This is because the desorption energy is at least 0.6 $\mathrm{eV}$ and increases with decreasing water coverage (i.e., hydration $)^{55}$ which does not agree with our findings. The hysteresis of the charge carrier dynamics observed upon dehydration/rehydration of titania and rather low apparent activation energies suggest that association of the oxide with adsorbed water can account for these phenomena. When temperature increases, hydrogen bonding among adsorbed water molecules ${ }^{56}$ and between water and oxide becomes weaker. This destabilizes trapped charge carriers, increases their recombination rates, and results in the apparent activation energy. When association of adsorbed water is perturbed above $423 \mathrm{~K}$, electron-hole recombination becomes temperatureindependent. The absence of apparent activation energy for the electron absorption decay at temperatures below $273 \mathrm{~K}$ (Figure 6f) can be understood by assessing the strength of hydrogen bonding through the shifts of the stretching $\mathrm{O}-\mathrm{H}$ frequencies. ${ }^{56}$ As the $\mathrm{O}-\mathrm{H}$ bands positions and intensities of sample $\mathrm{i}$ were almost identical at 153 and $263 \mathrm{~K}$ (Figure S8, Supporting Information), hydrogen bonding is expected to be similar in both cases. When association does not change with temperature the electron-hole recombination rates remain constant.

3.7. Computational Analysis of the Surface-Trapped Hole Migration on Anatase $\mathrm{TiO}_{2}(101)$. Our experimental results showed that the decay rates of photogenerated electron absorption in $\mathrm{TiO}_{2}$ P25 depend strongly on the hydration state of titania and hydrogen bonding between the oxide and adsorbed water. These findings suggest that the slowed down charge carrier recombination rates in hydrated n-type $\mathrm{TiO}_{2}$ originate from the interaction of adsorbed water with surface- 
trapped holes rather than with electrons. This is because all $\mathrm{TiO}_{2}$ samples exhibited hysteresis of the electron absorption dynamics at temperatures above $423 \mathrm{~K}$ irrespective of the nature of photogenerated electrons (Figure 6). For instance, the photogenerated electron absorption signal in the oxidized sample v was dominated by STE up to $523 \mathrm{~K}$. Nonetheless, the electron absorption decay rates in this sample were temperature-independent above $423 \mathrm{~K}$. This hysteresis can be understood by taking into account the recent finding of Panarelli et al., who observed that the surface-trapped holes disappear from the EPR spectra when water was desorbed from $\mathrm{TiO}_{2}$ at $423 \mathrm{~K}^{17}$ This was interpreted in terms of stabilization of surface-trapped holes by adsorbed water present on the oxide. Suppressed charge carrier recombination at the picosecond time scale due to trapping of photogenerated holes by water adsorbed on anatase nanoparticles has also been reported by Shirai et al. recently. ${ }^{27}$ These observations agree with the expected interaction of adsorbed water molecules with photogenerated holes that are driven to the surface in hydrated $\mathrm{TiO}_{2}{ }^{3}$

In order to better understand how associated adsorbed water interacts with photogenerated holes in the studied titania samples and suppresses charge carrier recombination, we complimented our experimental results with computational methods. To this end, we studied the migration of a photogenerated hole trapped on the anatase $\mathrm{TiO}_{2}(101)$ surface by an ab initio DFT $+U$ analysis. This model was chosen because the anatase phase constitutes ca. 84 wt $\%$ of used $\mathrm{TiO}_{2}$ P25 and (101) is the most stable and abundant anatase facet. The dehydrated sample was represented by a clean $\mathrm{TiO}_{2}(101)$ surface while the hydrated material was modeled by adding 12 associated water molecules to the system. Some of these water molecules adsorbed dissociatively forming surface hydroxyls. The (101) surface exhibits three types of oxygen atoms: twofold-coordinated bridge oxygen $\left(\mathrm{O}_{2 \mathrm{c}}\right)$, threefold-coordinated surface $\left(\mathrm{O}_{3 c(a)}\right)$, and threefold-coordinated subsurface $\left(\mathrm{O}_{3 c(b)}\right)$ atoms, as well as sixfold $\left(\mathrm{Ti}_{6 c}\right)$ - and fivefold $\left(\mathrm{Ti}_{5 \mathrm{c}}\right)$ coordinated titanium (Figure S2, Supporting Information).

The surface-trapped hole $\left(\mathrm{h}^{+}\right)$was constructed by removing an electron from the $\mathrm{TiO}_{2}$ slab. The formed charge was compensated with a uniform background of charge of the opposite sign, and then the system was allowed to relax. In the dehydrated system the hole localized on $\mathrm{O}_{2 \mathrm{c}}$ had $0.28 \mathrm{eV}$ lower energy than on $\mathrm{O}_{3 c}$ (b) site, while no stable configuration was found for the hole trapped on the $\mathrm{O}_{3 \mathrm{c}(\mathrm{a})}$ atom. For the hydrated system the situation was substantially different. Namely, the most energetically favorable localizations of the hole were $\mathrm{O}_{2 c}$ (Figure 7, parts a and $\mathrm{d}$ ) and $\mathrm{O}_{3 \mathrm{c}(\mathrm{b})}$ (Figure 7, parts $\mathrm{c}$ and e) atoms (the latter was only $0.03 \mathrm{eV}$ lower in energy), while the hole localized on $\mathrm{O}_{3 \mathrm{c}(\mathrm{a})}$ was ca. $0.5 \mathrm{eV}$ higher in energy than either of these two sites. When the hole was localized on the $\mathrm{O}_{3 \mathrm{c}(\mathrm{b})}$ atom, the corresponding $\mathrm{Ti}_{5 \mathrm{c}}-\mathrm{O}$ bond broke, which resulted in the formation of a fourfold-coordinated $\mathrm{Ti}$ atom. In the dehydrated system this atom was thermodynamically unstable. On the other hand, water adsorbed on the $\mathrm{Ti}_{5 c}$ site stabilized this undercoordinated $\mathrm{Ti}$ atom in the hydrated system. The bond rearrangement upon migration of $\mathrm{h}^{+}$from the $\mathrm{O}_{2 \mathrm{c}}$ site to $\mathrm{O}_{3 \mathrm{c}(\mathrm{b})}$ site in the hydrated system is shown in Figure 7, parts $\mathrm{d}$ and e. The $\mathrm{Ti}_{5 \mathrm{c}}-\mathrm{O}_{3 \mathrm{c}(\mathrm{b})}$ bond length was 2.08 and $2.31 \AA$ when the hole localized on the $\mathrm{O}_{2 c}$ and $\mathrm{O}_{3 c(b)}$ sites, respectively. These differences in hole localization on clean and hydrated anatase $\mathrm{TiO}_{2}(101)$ agreed well with the works of Selloni and co-workers. ${ }^{57,58}$

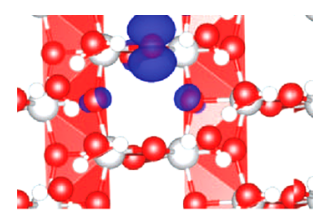

(a) $\mathrm{h}^{+}-\mathrm{O}_{2 \mathrm{c}}$

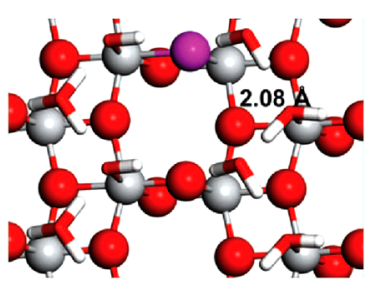

(d) $\mathrm{h}^{+}-\mathrm{O}_{2 \mathrm{c}}$

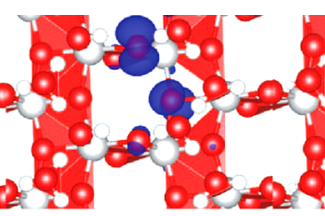

(b) TS

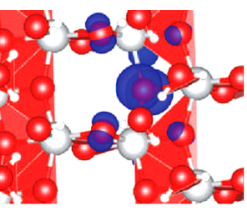

(c) $\mathrm{h}^{+}-\mathrm{O}_{3 \mathrm{c}(\mathrm{b})}$

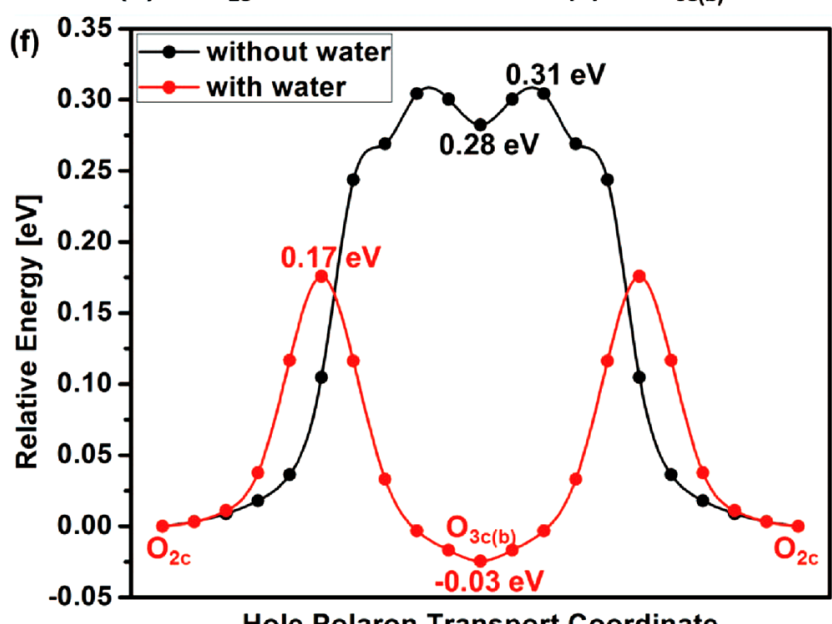

Hole Polaron Transport Coordinate

Figure 7. Migration of the hole $\left(\mathrm{h}^{+}\right)$trapped at the anatase $\mathrm{TiO}_{2}(101)$ surface along the transport coordinate as defined in Figure S2b. (a and c) Spin density of $\mathrm{h}^{+}$localized into the $\mathrm{O}_{2 \mathrm{c}}$ and $\mathrm{O}_{3 \mathrm{c}(\mathrm{b})}$ sites. (b) Spin density of the transition state for $\mathrm{h}^{+}$migration from $\mathrm{O}_{2 c}$ to $\mathrm{O}_{3 \mathrm{c}(\mathrm{b})}$ site. (d and e) Configurations of $\mathrm{h}^{+}$localized into the $\mathrm{O}_{2 \mathrm{c}}$ and $\mathrm{O}_{3 \mathrm{c}(\mathrm{b})}$ sites. (f) Potential energy surfaces of $\mathrm{h}^{+}$migration on the $\mathrm{TiO}_{2}(101)$ surface with and without adsorbed water.

In order to evaluate whether adsorbed water affects mobility of the hole trapped on the anatase $\mathrm{TiO}_{2}(101)$ surface, we investigated its migration along the $\mathrm{O}_{2 c}-\mathrm{O}_{3 c}(\mathrm{~b})-\mathrm{O}_{2 c}$ pathway (Figure S2, Supporting Information). We chose this trajectory because the alternative path would involve the $\mathrm{O}_{3 c(a)}$ atom which was energetically substantially less favorable for the $\mathrm{h}^{+}$ localization on both clean and hydrated surfaces. The results of this analysis are shown in Figure 7. First of all, we found that the transition state was shared between $\mathrm{O}_{2 c}$ and $\mathrm{O}_{3 c(b)}$ atoms (Figure $7 \mathrm{~b}$ ), which agreed well with a previous study of the hole transfer from anatase $\mathrm{TiO}_{2}(101)$ to a surface hydroxyl. ${ }^{57}$ The barriers for the hole migration from $\mathrm{O}_{2 c}$ to $\mathrm{O}_{3 c(b)}$ in dehydrated and hydrated systems were 0.31 and $0.17 \mathrm{eV}$, respectively. Beside the higher barrier, hole migration on the clean $\mathrm{TiO}_{2}(101)$ surface involved the unfavorable $\mathrm{O}_{3 \mathrm{c}(\mathrm{b})}$ site (Figure $7 \mathrm{f}$ ). From this, one can expect a substantially higher mobility of the surface-trapped holes in hydrated titania compared with dehydrated samples. This higher mobility can also account for lower charge carrier recombination rates observed for hydrated $\mathrm{TiO}_{2} .{ }^{59}$ Besides this, the difference between the theoretical barriers of the hole migration in dehydrated and hydrated systems was ca. $0.1-0.2 \mathrm{eV}$ (Figure $7 \mathrm{f}$ ), in keeping with the experimental apparent activation energies (Figure 6). These 
results support our hypothesis that the apparent activation energies obtained in the present work for the hydrated samples originate from the hydrogen-bond interaction between the adsorbed water and titania. Moreover, the difference between the surface-trapped hole mobility in dehydrated and hydrated systems can account for the hysteresis of the charge carrier dynamics upon dehydration of $\mathrm{TiO}_{2}$ (Figure 6).

\section{CONCLUSION}

The influence of $\mathrm{TiO}_{2}$ P25 hydration on the decay rates of photogenerated electron absorption at the millisecond to minute time scale was investigated by rapid scan time-resolved DRIFT spectroscopy. Dehydrated titania exhibited a weaker electron absorption signal which decayed at higher rates compared with hydrated samples. The slowest electron absorption decay was found for $\mathrm{TiO}_{2}$ after an oxidation treatment. The photogenerated electron absorption feature formed under $325 \mathrm{~nm}$ UV laser irradiation in untreated and oxidized $\mathrm{TiO}_{2}$ was dominated by contributions from conduction band electrons (CBE) and shallow trapped electrons (STE), respectively. Charge carrier recombination rates in hydrated samples increased with temperature in the 293-423 K range with low apparent activation energies between 0.06 and $0.17 \mathrm{eV}$. Higher values were found for samples containing more water. The electron absorption decay rates became temperature-independent at $T>423 \mathrm{~K}$ and $T<273 \mathrm{~K}$. At high temperature a perturbed interaction between adsorbed water and the oxide surface resulted in the temperature-independent charge carrier recombination, while below $273 \mathrm{~K}$ this was due to constant strength of hydrogen bonding between titania and adsorbed water. The experimental results were complemented by an ab initio DFT $+U$ analysis of surface-trapped hole migration on dehydrated and hydrated anatase $\mathrm{TiO}_{2}(101)$. This analysis revealed that adsorption of water stabilizes holes localized on surface oxygen atoms and lowers hole migration barriers. These effects are expected to increase charge carrier mobility and with that suppress electron-hole recombination. On the basis of our experimental and theoretical findings we conclude that the apparent activation energies obtained in this study originate from hydrogen-bonding interactions between adsorbed water and $\mathrm{TiO}_{2}$, which in turn are involved in the stabilization of surface-trapped holes leading to the observed prolonged lifetime of photogenerated electrons.

\section{ASSOCIATED CONTENT}

\section{S Supporting Information}

The Supporting Information is available free of charge on the ACS Publications website at DOI: 10.1021/acs.jpcc.7b00472.

Constructed anatase $\mathrm{TiO}_{2}(101)$ surface, TEM images, survey and difference DRIFT spectra, XRD patterns, UV-vis spectra, and detailed data processing (PDF)

\section{AUTHOR INFORMATION}

\section{Corresponding Authors}

*E-mail: E.J.M.Hensen@tue.nl. Phone: +31 0402475178.

*E-mail: J.P.Hofmann@tue.nl. Phone: +31 0402473466.

ORCID $\odot$

Emiel J. M. Hensen: 0000-0002-9754-2417

Jan P. Hofmann: 0000-0002-5765-1096

Notes

The authors declare no competing financial interest.

\section{ACKNOWLEDGMENTS}

The authors thank Dr. Heinz Frei of Lawrence Berkeley National Lab, U.S.A. for fruitful discussions as well as Johan J. G. van Velzen and Tiny W. G. M. Verhoeven (both Eindhoven University of Technology) for their help in setting up the equipment. Development of the time-resolved FTIR setup was supported by the Dutch National Research School Combination Catalysis Controlled by Chemical Design (NRSC-C). This work was supported by NanoNextNL, a micro and nanotechnology consortium of the Government of The Netherlands and 130 partners: project NNNL.02B.08CO2Fix-1.

\section{REFERENCES}

(1) Osterloh, F. E. Inorganic Nanostructures for Photoelectrochemical and Photocatalytic Water Splitting. Chem. Soc. Rev. 2013, 42, 2294-2320.

(2) Qiao, J.; Liu, Y.; Hong, F.; Zhang, J. A Review of Catalysts for the Electroreduction of Carbon Dioxide to Produce Low-Carbon Fuels. Chem. Soc. Rev. 2014, 43, 631-675.

(3) Schneider, J.; Matsuoka, M.; Takeuchi, M.; Zhang, J.; Horiuchi, Y.; Anpo, M.; Bahnemann, D. W. Understanding $\mathrm{TiO}_{2}$ Photocatalysis: Mechanisms and Materials. Chem. Rev. 2014, 114, 9919-9986.

(4) Ma, Y.; Wang, X.; Jia, Y.; Chen, X.; Han, H.; Li, C. Titanium Dioxide-Based Nanomaterials for Photocatalytic Fuel Generations. Chem. Rev. 2014, 114, 9987-10043.

(5) Grätzel, M. Dye-Sensitized Solar Cells. J. Photochem. Photobiol., C 2003, 4, 145-153.

(6) Lee, S. Y.; Park, S. J. $\mathrm{TiO}_{2}$ Photocatalyst for Water Treatment Applications. J. Ind. Eng. Chem. 2013, 19, 1761-1769.

(7) Ngamsinlapasathian, S.; Sreethawong, T.; Suzuki, Y.; Yoshikawa, S. Single- and Double-Layered Mesoporous $\mathrm{TiO}_{2} / \mathrm{P} 25 \mathrm{TiO}_{2}$ Electrode for Dye-Sensitized Solar Cell. Sol. Energy Mater. Sol. Cells 2005, 86, 269-282.

(8) Szczepankiewicz, S. H.; Moss, J. A.; Hoffmann, M. R. Slow Surface Charge Trapping Kinetics on Irradiated $\mathrm{TiO}_{2}$. J. Phys. Chem. $B$ 2002, 106, 2922-2927.

(9) Szczepankiewicz, S. H.; Colussi, A. J.; Hoffmann, M. R. Infrared Spectra of Photoinduced Species on Hydroxylated Titania Surfaces. J. Phys. Chem. B 2000, 104, 9842-9850.

(10) Warren, D. S.; McQuillan, A. J. Influence of Adsorbed Water on Phonon and UV-Induced IR Absorptions of $\mathrm{TiO}_{2}$ Photocatalytic Particle Films. J. Phys. Chem. B 2004, 108, 19373-19379.

(11) Yamakata, A.; Ishibashi, T. A.; Onishi, H. Time-Resolved Infrared Absorption Spectroscopy of Photogenerated Electrons in Platinized $\mathrm{TiO}_{2}$ Particles. Chem. Phys. Lett. 2001, 333, 271-277.

(12) Panayotov, D. A.; Yates, J. T. N-Type Doping of $\mathrm{TiO}_{2}$ with Atomic Hydrogen-Observation of the Production of Conduction Band Electrons by Infrared Spectroscopy. Chem. Phys. Lett. 2007, 436, 204208.

(13) MacDonald, I. R.; Rhydderch, S.; Holt, E.; Grant, N.; Storey, J. M. D.; Howe, R. F. EPR Studies of Electron and Hole Trapping in Titania Photocatalysts. Catal. Today 2012, 182, 39-45.

(14) Martin, S. T.; Herrmann, H.; Choi, W.; Hoffmann, M. R. TimeResolved Microwave Conductivity. Part 1. - $\mathrm{TiO}_{2}$ Photoreactivity and Size Quantization. J. Chem. Soc., Faraday Trans. 1994, 90, 33153322.

(15) Wang, X.; Feng, Z.; Shi, J.; Jia, G.; Shen, S.; Zhou, J.; Li, C. Trap States and Carrier Dynamics of $\mathrm{TiO}_{2}$ Studied by Photoluminescence Spectroscopy under Weak Excitation Condition. Phys. Chem. Chem. Phys. 2010, 12, 7083.

(16) Wang, X.; Kafizas, A.; Li, X.; Moniz, S. J. A.; Reardon, P. J. T.; Tang, J.; Parkin, I. P.; Durrant, J. R. Transient Absorption Spectroscopy of Anatase and Rutile: The Impact of Morphology and Phase on Photocatalytic Activity. J. Phys. Chem. C 2015, 119, 1043910447.

(17) Panarelli, E. G.; Livraghi, S.; Maurelli, S.; Polliotto, V.; Chiesa, M.; Giamello, E. Role of Surface Water Molecules in Stabilizing 
Trapped Hole Centres in Titanium Dioxide (Anatase) as Monitored by Electron Paramagnetic Resonance. J. Photochem. Photobiol., A 2016, 322-323, 27-34.

(18) Zhang, Z.; Yates, J. T. Direct Observation of Surface-Mediated Electron-Hole Pair Recombination in $\mathrm{TiO}_{2}$ (110). J. Phys. Chem. C 2010, 114, 3098-3101.

(19) Zhang, M.; de Respinis, M.; Frei, H. Time-Resolved Observations of Water Oxidation Intermediates on a Cobalt Oxide Nanoparticle Catalyst. Nat. Chem. 2014, 6, 362-367.

(20) Zandi, O.; Hamann, T. W. Determination of Photoelectrochemical Water Oxidation Intermediates on Haematite Electrode Surfaces Using Operando Infrared Spectroscopy. Nat. Chem. 2016, 8, 778-783.

(21) Herlihy, D. M.; Waegele, M. M.; Chen, X.; Pemmaraju, C. D.; Prendergast, D.; Cuk, T. Detecting the Oxyl Radical of Photocatalytic Water Oxidation at an $\mathrm{N}-\mathrm{SrTiO}_{3} /$ aqueous Interface through Its Subsurface Vibration. Nat. Chem. 2016, 8, 549-555.

(22) Pankove, J. Optical Processes in Semiconductors; Prentice-Hall: Englewood Cliffs, NJ, 1971.

(23) Iwata, K.; Takaya, T.; Hamaguchi, H. O.; Yamakata, A.; Ishibashi, T. A.; Onishi, $\mathrm{H}$.; Kuroda, $\mathrm{H}$. Carrier Dynamics in $\mathrm{TiO}_{2}$ and $\mathrm{Pt} / \mathrm{TiO}_{2}$ Powders Observed by Femtosecond Time-Resolved nearInfrared Spectroscopy at a Spectral Region of 0.9-1.5 Mm with the Direct Absorption Method. J. Phys. Chem. B 2004, 108, 20233-20239.

(24) Kukimoto, H.; Shionoya, S.; Koda, T.; Hioki, R. Infrared Absorption due to Donor States in ZnS Crystals. J. Phys. Chem. Solids 1968, 29, 935-944.

(25) Panayotov, D. A.; Burrows, S. P.; Morris, J. R. Infrared Spectroscopic Studies of Conduction Band and Trapped Electrons in UV-Photoexcited, H-Atom N-Doped, and Thermally Reduced $\mathrm{TiO}_{2}$. J. Phys. Chem. C 2012, 116, 4535-4544.

(26) Tachibana, Y.; Umekita, K.; Otsuka, Y.; Kuwabata, S. Charge Recombination Kinetics at an in Situ Chemical Bath-Deposited Cds/ nanocrystalline $\mathrm{TiO}_{2}$ Interface. J. Phys. Chem. C 2009, 113, 68526858 .

(27) Shirai, K.; Sugimoto, T.; Watanabe, K.; Haruta, M.; Kurata, H.; Matsumoto, Y. Effect of Water Adsorption on Carrier Trapping Dynamics at the Surface of Anatase $\mathrm{TiO}_{2}$ Nanoparticles. Nano Lett. 2016, 16, 1323-1327.

(28) Furube, A.; Asahi, T.; Masuhara, H.; Yamashita, H.; Anpo, M. Charge Carrier Dynamics of Standard $\mathrm{TiO}_{2}$ Catalysts Revealed by Femtosecond Diffuse Reflectance Spectroscopy. J. Phys. Chem. B 1999, 103, 3120-3127.

(29) Kresse, G.; Hafner, J. Ab Initio Molecular-Dynamics Simulation of the Liquid-Metal-amorphous-Semiconductor Transition in Germanium. Phys. Rev. B: Condens. Matter Mater. Phys. 1994, 49, 1425114269.

(30) Blöchl, P. E. Projector Augmented-Wave Method. Phys. Rev. B: Condens. Matter Mater. Phys. 1994, 50, 17953-17979.

(31) Perdew, J. P.; Burke, K.; Ernzerhof, M. Generalized Gradient Approximation Made Simple. Phys. Rev. Lett. 1996, 77, 3865-3868.

(32) Dudarev, S. L.; Botton, G. A.; Savrasov, S. Y.; Humphreys, C. J.; Sutton, A. P. Electron-Energy-Loss Spectra and the Structural Stability of Nickel Oxide: An LSDA+U Study. Phys. Rev. B: Condens. Matter Mater. Phys. 1998, 57, 1505-1509.

(33) Morgan, B. J.; Watson, G. W. Polaronic Trapping of Electrons and Holes by Native Defects in Anatase $\mathrm{TiO}_{2}$. Phys. Rev. B: Condens. Matter Mater. Phys. 2009, 80, 233102.

(34) Morgan, B. J.; Watson, G. W. Intrinsic n-Type Defect Formation in $\mathrm{TiO}_{2}$ : A Comparison of Rutile and Anatase from GGA+ U Calculations. J. Phys. Chem. C 2010, 114, 2321-2328.

(35) Henkelman, G.; Jónsson, H. Improved Tangent Estimate in the Nudged Elastic Band Method for Finding Minimum Energy Paths and Saddle Points. J. Chem. Phys. 2000, 113, 9978.

(36) Sheppard, D.; Terrell, R.; Henkelman, G. Optimization Methods for Finding Minimum Energy Paths. J. Chem. Phys. 2008, $128,134106$.
(37) Jackson, P.; Parfitt, G. D. Infra-Red Study of the Surface Properties of Rutile. Water and Surface Hydroxyl Species. Trans. Faraday Soc. 1971, 67, 2469.

(38) Yates, D. J. C. Infrared Studies of the Surface Hydroxyl Groups on Titanium Dioxide, and of the Chemisorption of Carbon Monoxide and Carbon Dioxide. J. Phys. Chem. 1961, 65, 746-753.

(39) Van Thiel, M.; Becker, E. D.; Pimentel, G. C. Infrared Studies of Hydrogen Bonding of Water by the Matrix Isolation Technique. J. Chem. Phys. 1957, 27, 486.

(40) Lange's Handbook of Chemistry, 15th ed.; Dean, J. A., Ed.; McGraw-Hill: New York, 1999; p 1466.

(41) Araña, J.; Doña-Rodríguez, J. M.; Cabo, C. G. I.; González-Díaz, O.; Herrera-Melián, J. A.; Pérez-Peña, J. FTIR Study of Gas-Phase Alcohols Photocatalytic Degradation with $\mathrm{TiO}_{2}$ and $\mathrm{AC}-\mathrm{TiO}_{2}$. Appl. Catal., B 2004, 53, 221-232.

(42) Lin, H.; Long, J.; Gu, Q.; Zhang, W.; Ruan, R.; Li, Z.; Wang, X. In Situ IR Study of Surface Hydroxyl Species of Dehydrated $\mathrm{TiO}_{2}$ : Towards Understanding Pivotal Surface Processes of $\mathrm{TiO}_{2}$ Photocatalytic Oxidation of Toluene. Phys. Chem. Chem. Phys. 2012, 14, 9468.

(43) Finnie, K. S.; Cassidy, D. J.; Bartlett, J. R.; Woolfrey, J. L. IR Spectroscopy of Surface Water and Hydroxyl Species on Nanocrystalline $\mathrm{TiO}_{2}$ Films. Langmuir 2001, 17, 816-820.

(44) Primet, M.; Pichat, P.; Mathieu, M. V. Infrared Study of the Surface of Titanium Dioxides. I. Hydroxyl Groups. J. Phys. Chem. 1971, 75, 1216-1220.

(45) Henderson, M. A. An HREELS and TPD Study of Water on $\mathrm{TiO}_{2}$ (110): The Extent of Molecular versus Dissociative Adsorption. Surf. Sci. 1996, 355, 151-166.

(46) Nakamura, R.; Ueda, K.; Sato, S. In Situ Observation of the Photoenhanced Adsorption of Water on $\mathrm{TiO}_{2}$ Films by SurfaceEnhanced IR Absorption Spectroscopy. Langmuir 2001, 17, 22982300.

(47) Griffiths, D. M.; Rochester, C. H. Infrared Study of the Adsorption of Water on to the Surface of Rutile. J. Chem. Soc., Faraday Trans. 1 1977, 73, 1510

(48) Czekaj, I.; Wambach, J.; Kröcher, O. Modelling Catalyst Surfaces Using DFT Cluster Calculations. Int. J. Mol. Sci. 2009, 10, 4310-4329.

(49) Maira, A.; Coronado, J.; Augugliaro, V.; Yeung, K. L.; Conesa, J. C.; Soria, J. Fourier Transform Infrared Study of the Performance of Nanostructured $\mathrm{TiO}_{2}$ Particles for the Photocatalytic Oxidation of Gaseous Toluene. J. Catal. 2001, 202, 413-420.

(50) Murphy, W. F.; Bernstein, H. J. Raman Spectra and an Assignment of the Vibrational Stretching Region of Water. J. Phys. Chem. 1972, 76, 1147-1152.

(51) Du, Q.; Superfine, R.; Freysz, E.; Shen, Y. R. Vibrational Spectroscopy of Water at the Vapor/water Interface. Phys. Rev. Lett. 1993, 70, 2313-2316.

(52) Yamakata, A.; Ishibashi, T.; Onishi, H. Water- and OxygenInduced Decay Kinetics of Photogenerated Electrons in $\mathrm{TiO}_{2}$ and $\mathrm{Pt} /$ $\mathrm{TiO}_{2}$ : A Time-Resolved Infrared Absorption Study. J. Phys. Chem. B 2001, 105, 7258-7262.

(53) Yamakata, A.; Ishibashi, T.; Onishi, H. Electron- and HoleCapture Reactions on $\mathrm{Pt} / \mathrm{TiO}_{2}$ Photocatalyst Exposed to Methanol Vapor Studied with Time-Resolved Infrared Absorption Spectroscopy. J. Phys. Chem. B 2002, 106, 9122-9125.

(54) Belhadj, H.; Hakki, A.; Robertson, P. K. J.; Bahnemann, D. W. In Situ ATR-FTIR Study of $\mathrm{H}_{2} \mathrm{O}$ and $\mathrm{D}_{2} \mathrm{O}$ Adsorption on $\mathrm{TiO}_{2}$ under UV Irradiation. Phys. Chem. Chem. Phys. 2015, 17, 22940-22946.

(55) Smith, R. S.; Li, Z.; Chen, L.; Dohnálek, Z.; Kay, B. D. Adsorption, Desorption, and Displacement Kinetics of $\mathrm{H}_{2} \mathrm{O}$ and $\mathrm{CO}_{2}$ on $\mathrm{TiO}_{2}(110)$. J. Phys. Chem. B 2014, 118, 8054-8061.

(56) Ford, T. A.; Falk, M. Hydrogen Bonding in Water and Ice. Can. J. Chem. 1968, 46, 3579-3586.

(57) Chen, J.; Li, Y.-F.; Sit, P.; Selloni, A. Chemical Dynamics of the First Proton-Coupled Electron Transfer of Water Oxidation on $\mathrm{TiO}_{2}$ Anatase. J. Am. Chem. Soc. 2013, 135, 18774-18777. 
(58) Di Valentin, C.; Selloni, A. Bulk and Surface Polarons in Photoexcited Anatase $\mathrm{TiO}_{2}$. J. Phys. Chem. Lett. 2011, 2, 2223-2228. (59) Ebenhoch, B.; Thomson, S. A. J.; Genevičius, K.; Juška, G.; Samuel, I. D. W. Charge Carrier Mobility of the Organic Photovoltaic Materials PTB7 and $\mathrm{PC}_{71} \mathrm{BM}$ and Its Influence on Device Performance. Org. Electron. 2015, 22, 62-68. 